\title{
fragmentos sobre universos fragmentados: mídia e têmporalidade
}

\author{
Anna Maria Balogh \\ Professora do Departamento de Cinema, \\ Rádio e Televisão na ECA-USP
}

\begin{abstract}
Time and space are fundamental in film making.
In this article we try to achieve a better understanding of time in film art, mostly connected with narrative and editing.
\end{abstract}

KEY WORDS: Cinema - Temporality - Setting up - Narrative.

\section{O Admirável Mundo Novo}

As formas de representação mais peculiares da era contemporânea, tais como o cinema, a TV, o vídeo, a computação gráfica, pressupõem a ilusão do movimento (/dinamicidade/). Assim sendo, esse universo de imagens se contrapõe ao prévio caracterizado pela /estaticidade/, pela ausência de movimento, como ocorre na pintura, na escultura, na arquitetura.

Como Géza Számosi bem observa em seu livro Tempo e Espaço: as dimensões gêmeas, o mundo novo traz alterações substanciais nas concepções prévias de tempo e espaço. Neste artigo, o nosso interesse se concentra no primeiro, muito embora, em muitos aspectos, as duas dimensões sejam inseparáveis. As mudanças se manifestam tanto na arte, 
com o cubismo na pintura, por exemplo, quanto na ciência, com a teoria da relatividade, por exemplo. Uma quarta dimensão, o tempo, se insere no universo antes dominado pela geometria euclidiana.

A questão da temporalidade está de tal modo presente em nossa vida, que dificulta as reflexões sobre o tema. Para tanto, vamos recorrer aos preciosos insighls de renomados pensadores contemporâneos como ponto de partida.

Para Paul Virilio, a velocidade e a fragmentação constituem elementos definidores da nossa época. Octavio Paz, pela via da crítica literária, chega a uma conclusão próxima quando diz que a modernidade traz consigo a aceleração do tempo e a pluralidade (de fatos, tendências, todas ocorrendo simultaneamente). Para Giles Deleuze, o cinema é essencialmente imagem-tempo, imagem-movimento. Para Alejo Carpentier, a América Latina se caracteriza pela convivência num mesmo espaço de tempos tão diferentes quanto a Idade da Pedra e a Idade Moderna. Basta pensar no Brasil onde o homem-gabiru coexiste com o executivo da avenida Paulista. De uma forma geral, as reflexões nos revelam que a tecnologia determina a desterritorialização do mundo contemporâneo, o espaço se pulveriza e o tempo predomina como categoria fundamental para a compreensão do admirável mundo novo em que vivemos. ${ }^{1}$

Além da complexidade da reflexão sobre a questão do tempo, temos que nos defrontar com outra, tema do artigo: a reflexão sobre relação da temporalidade com uma área específica de saber, a comunicação. Assim sendo, vamos pensar sobre a relação entre a temporalidade c a mídia, aquela que envolve o som e a imagem em movimento.

A própria evolução diacrônica desses meios de comunicação de massas já pressupõe um contexto bastante amplo que podemos exemplificar com a mais tradicional delas, o cinema, recorrendo a um

\footnotetext{
1. Para a recolecção de idéias sobre o tempo, recorremos sobretudo às seguintes obras: VIRILIO e LOTRINGER (1984); PAZ (1974); DELEUZE (1985; 1986).
} 
trecho de Jorge Urrutia em que ele comenta as concepções sobre a sétima arte de Riciotto Canudo:

"Puede comprenderse el cine como la culminación de una línea de búsqueda científica desarrollada desde 1826, fecha de la primera. fotografía hecha del natural por Joseph Nicéphore Niepce, hasta 1985, sin olvidar la antigua tradición de las sombras chinescas. Pero también es el cine el abocamiento del proceso artístico del siglo XIX, en busca de la experimentación perspectivizada de la realidad, la acción y el movimiento" (URRUTIA, 1984:126).

Relacionar o tempo com a mídia significa, portanto, relacionar a questão da temporalidade com formas de representação do som e da imagem resultantes de uma evolução dupla e complexa: a tecnológica e a artística, ambas em constante diálogo. Este diálogo se acirra com as possibilidades mais amplas trazidas pelo advento da tecnologia eletrônica, sobretudo na TV e na computação gráfica.

\section{Tempo, Tecnologia e Mídia}

A tecnologia interfere diretamente sobre as formas de representação atuais, assim como sobre as próprias estratégias de recepção dessas imagens representadas.

Conquistas tecnológicas como o satélite c a antena parabólica permiti ram que a TV chegasse aos lugares mais longínquos da terra - /expansão no espaço/ - em um tempo recorde - /aceleração no tempo/ Acontecimentos como as Olimpíadas, os casamentos reais, a guerra do golfo, chegam hoje a todos os lares através da TV.

Mesmo se nos ativermos apenas aos equipamentos mais acessíveis c mais utilizados, veremos que tanto as condições de realização, quanto as condições de recepção das imagens contemporâneas mudaram muito em relação ao passado. 
No cinema tradicional, qualquer tipo de transformação da imagem exigia, em geral, um processo demorado e dispendioso. Hoje, na televisão, um simples switcher permite uma alteração extremamente rápida da imagem original captada pelas câmeras. Imagens superpostas, negativadas, solarizadas, "mosaicadas", fazem parte do quotidiano do espectador.

Qualquer mortal, proprietário de um VHS, pode hoje tomar uma imagem mais lenta, mais rápida, congelar a imagem, gravar a imagem. Tais procedimentos faziam parte, no passado, dos privilégios exclusivos dos realizadores. $\mathrm{Na}$ atualidade, o espectador interfere de forma mais clara no processo da enunciação. Grande parte das intervenções do espectador mencionadas tem relação muito estreita com a manipulação do tempo: acelerar, desacelerar, congelar, gravar. Um fazer que altera seja o ritmo proposto para a veiculação das imagens, seja o momento proposto para a fruição das mesmas.

O controle remoto transformou a interface com o espectador. O antigo olhar era de aspecto durativo, olhar de "videota passivo mesmerizado" pela TV. Hoje o zapping propicia um olhar iterativo, com o controle remoto o espectador vai saltitando de canal a canal. As TVs picture in picture, por outro lado, tomam possível assistir a vários programas, o que antes se fazia de forma alternada ou seletiva.

A tecnologia eletrônica acaba determinando um processo de aceleração temporal que, em termos de recepção, interfere poderosamente nas estratégias de consumo dos discursos audiovisuais. Uma observação de Ornar Calabrese na revista Análisi é bastante ilustrativa nesse sentido:

"En Italia se ha calculado que cinco anos de existencia de Ias televisiones privadas han consumido el patrimonio de noventa anos de cine.ficción. Muy rapidamente, pues, se ha pasado dei consumo televisivo de productos nuevos a la relectura cada vez mayor de productos viejos" (CALABRESE, 1984: 88). 


\section{O Tempo e a Sintaxe do Discurso Audiovisual}

0 próprio processo de organização do discurso audiovisual tem uma relação muito instigante com a questão da temporalidade em vários aspectos. $^{2}$

A concepção de montagem do cinema tradicional, sobretudo o americano, vê o agenciamento sintático dos planos de um filme como um processo em que prevalece o sentido da harmonia. A chamada "dccupagem clássica" pressupõe um espectador a ser levado pela mão do realizador para dentro da tela. Nesse tipo de decupagem, entre outros aspectos relevantes, há ênfase na /continuidade/, na minimização das interrupções representadas pelos cortes entre planos. Existe a ilusão de um fluir temporal contínuo. Além disso, o olhar do espectador deve ser conduzido harmoniosamente do plano maior, cuja permanência na tela deve ser necessariamente mais longa, gradativamente aos planos menores, cuja permanência será tanto mais curta, quanto menor for o plano. Esta estratégia é direcionada a um espectador catárticamente ligado à narrativa filmica que essa forma de decupagem atualiza.

Como é óbvio, essa não é a única forma de organização sintática do discurso filmico; é, no entanto, a mais consagrada, tanto no cinema americano, quanto em realizadores como Pudovkin, no cinema de vanguarda soviético, por exemplo. Alguns realizadores e escolas, em diferentes momentos de diacronia do cinema, romperam com esse padrão. É o caso de Serguci Eisenstein, cuja montagem de atrações se caracteriza precisamente pela ênfase no corte, nos contrastes rítmicos, gráficos e outros na passagem de um plano a outro. Também a Nouve/le vague francesa, nos anos 60, deu ênfase à /descontinuidade/ da sintaxe filmica, desvelando seus artifícios, sobretudo em filmografias como a de Jean Luc Godard.

\footnotetext{
2. "A montagem é essa operação que tem por objeto as imagens-movimento para extrair delas o todo, a idéia, isto é, a imagem do tempo", DELEUZE (1985: 44).
}

significação $11 / 12$ 
Grande parte da força das imagens filmicas nasce, pois, da tensão entre a natural /dcscontinuidade/ das imagens filmicas - que nunca são captadas na ordem seqüencial que adquirem na narrativa filmica final, mas na ordem seqüencial que a economia de produção dita -ca /ilusão de continuidade/ que a maioria das formas de montagem privilegia.

Aliás, repensando o processo de montagem (cinema) c de edição (TV e vídeo), em relação com a temporal idade, vamos estabelecer um saudável diálogo com pensadores de outras áreas, sobretudo com os ricos insights de Paul Virilio:

"Esta estética da interrupção que estrutura a consciência contemporânea é, na verdade, uma cinemática. Pois o cinema, a arte do contínuo, paradoxalmente, retira toda a sua energia da interrupção (VI'RILIO e LOTRINGER,

1984: 42, grifo meu).

A força da interrupção em meio à continuidade do discurso filmico como um todo foi a descoberta dos cineastas que pensaram subverter a decupagcm clássica. De qualquer modo, seja optando pela ênfase na continuidade, seja optando pela ênfase na descontinuidade na organização sintática do discurso filmico, nenhum cineasta pode escapar do fato de que o filme é exibido num continuum, do começo ao fim da sessão de cinema.

A televisão comercial, meio de comunicação já mais claramente inserido na acelerada temporalidade da tecnologia eletrônica, não pode prescindir de intervalos periódicos, as famosas janelas para os comerciais ("tempo é dinheiro"). A TV ê que assume, de forma muito mais evidente do que o cinema, essa estética da interrupção, também comentada por Paul Virilio:

"Nossa visão é a de uma montagem, uma montagem de temporalidades, que são produto não apenas dos poderes existentes, mas das tecnologias que organizam o tempo. É óbvio que a interrupção atua mais sobre a temporalidade que sobre o espaço "(VIRILIO, 1984: 42, grifo meu). 
As interrupções determinam uma divisão do conteúdo em blocos de sentido descontínuos, uma linguagem afeita a momentos de suspensão e de reatamento do sentido, uma estética de fragmentos, à qual Paul Virilio também está atento:

"Vemos que houve um deslocamento da unidade (a noção de unidade, de continuidade) para a noção de fragmento, de desordem e temos aí uma reversão " (VIRILIO, 1984:

43, grifo meu). ${ }^{3}$

\section{Edição Clip-Clip, o Frenesi Rítmico}

Para gerações que cresceram vendo um cinema tipo "kiss-kiss bang-bang", seguidores da "decupagem clássica", resulta bem estranha a frenética edição do videoclipe musical à qual as novas gerações estão afeitas. Em primeiro lugar, ao contrário dos filmes clássicos, não é a imagem que determina o ritmo da montagem, mas é o ritmo da música "pop" que comanda a sintaxe e o ritmo. Além disso, salvo alguns clipes mais tradicionais, ainda narrativos, a maioria deles revela uma tendência à "desnarrativação", à sucessão arbitrária e caótica de imagens que levou muitos críticos a associarem esse universo imagético a outro, o onírico, muito similar. Além disso, alguns críticos, como Marsha Kinder, atribuem o ritmo frenético de edição do clipe não só à prevalência da música sobre a imagem, como também a fatores extratextuais como o aumento do consumo de cocaína no meio da música "pop" e da mídia em geral como um dos maiores determinantes desse frenesi rítmico dos clipes. ${ }^{4}$

\footnotetext{
3. Em termos de uma visão mais clara da noção de "fragmento", consideramos a introdução de Octavio Paz em Corriente Alterna, muito esclarecedora: "Espero que, a pesar de su aparente dispersión, sea visible la unidad contraditória de estos fragmentos, todos ellos apuntan hacia un tema único: la aparición en nuestra historia de otro tiempo y otro espaço. Creo que el fragmento es la forma que mejor refleja esta realidad en movimento que vivimos y que somos. Más que una semilla, el fragmento es una partícula errante que sólo se define frente a otras partículas: no es nada sino una relación” (PAZ, 1969: 1). O que o ensaísta nos diz sobre os textos fragmentários do livro é extensivo ao universo igualmente fragmentado da mídia.

4. "The fast pace of MTV'S programming might also be connected with the rise of cocaine as the dominant drug in pop culture in place of acid and grass" (KINDER, 1987: 234).
} 


\section{O Tempo que o Discurso Oculta: as Elipses}

Décadas de cinema, televisão e vídeo deram ao espectador urna competência ponderável na descodificação dos discursos audiovisuais. Se nos primórdios do cinema foi necessário conduzir o espectador pela mão e mostrar claramente cada passo da narrativa, hoje é possível dar muitos elementos como sabidos, pressupostos, não é necessário mostrálos. Podemos fazer pequenos e grandes saltos no tempo sem prejudicar a inteligibilidade do discurso filmico.

O filme 2001: uma Odisséia no Espaço, de Stanley Kubrick (EUA, 1968), é um exemplo clássico. No início do filme, um primata descobre o potencial do osso como arma, mata alguns de seus semelhantes com o osso, para em seguida arremessá-lo ao ar. Na fusão das imagens subseqüentes o osso se transforma em marco de uma estação espacial em plena era contemporânea, e na passagem de um plano a outro houve um salto de séculos.

$\mathrm{Na}$ atualidade, tanto os avanços tecnológicos, quanto as mudanças políticas e econômicas acabam por imprimir ao mundo uma voracidade temporal sem precedentes.

Os meios de comunicação de massa aceleraram a divulgação e o consumo dos textos da cultura, acirraram as apropriações e as transformações intertextuais. Uma obra, assim como os meios técnicos que permitem sua veiculação, têm uma obsolescência programada, nada mais é eterno, como na arte prévia. Toma-se difícil distinguir os fragmentos de uma obra original em meio a tantas citações, apropriações e transformações. Temporalidades aparentemente irreconciliáveis passam a coexistir de modo ambíguo e paradoxal nos meios audiovisuais. Convém analisar esse fenômeno.

\section{Voracidade Temporal e Discursos Audiovisuais}

A filmografia tradicional geralmente abarcava temporalidades bastante claras em suas narrativas: a história da vida de um ou vários 
personagens, dẹ um período decisivo da vida de um personagem (ou vários), um período marcante da vida de alguns personagens e da história de um pais etc. Tirante algumas sagas e épicos, o período tratado geralmente não ultrapassava em muito o das décadas decisivas da trajetória de um personagem ou do acontecimento tratado.

Intolerância, de D. W. Griffith (EUA, 1916), pioneiro em tantos aspectos, também o foi no tratamento do tempo. Sob a moldura de um tema único - a intolerância do ser humano ao longo da história -, o realizador uniu num só filme tempos tão diversos quanto a época de Cristo, o século XX, o século XVI francês e a Mesopotâmia antes de Cristo. Trata-se, no entanto, de um exemplo raro para a época. Só mais recentemente, como vimos em 2001 uma Odisséia no Espaço, que o cinema faz ousadias na temporalização do discurso.

Dentro de uma tendência geral, contemporânea, de exacerbamento das transformações intertextuais de gêneros, estilos, linguagens, filmes que mesclam tendências do clipe, do noir, dos comerciais etc., há também um trabalho mais subversivo com o tempo e o espaço em muitos filmes e séries televisuais. Apontamos apenas alguns exemplos ilustrativos.

Um número razoável de obras filmicas recentes tem como temática principal a relação do homem com o tempo.

O Vingador do Futuro, de Paul Verhoven (EUA, 1990), traz a questão dos limites entre a realidade e a fantasia, a possibilidade de que as memórias que o operário Doug Quaid tem de Marte possam ser, de fato, memórias vividas, ou ainda, simples implantes, fantasias de memória colocadas em sua mente pela agência Recall, especializada nesse tipo de atividade. De Volta para o Futuro, de Robert Zemeckis, que já tem as seqüências II (EUA, 1989) e III (EUA, 1990), traz para Marty MacFly a oportunidade de voltar à juventude de seus pais e, aparentemente, de interferir na trajetória da vida deles e da sua própria.

Talvez o exemplo mais interessante dentro desse conjunto de filmes seja Peggy Sue - seu Passado a Espera, de Francis Ford Coppola 


\section{Anna Maria Balogh}

(EUA, 1986). A protagonista, Peggy Sue, ao ser coroada Rainha do $25^{\circ}$ aniversário de formatura de sua turma do colégio passa mal. É inexplicavelmente transportada dos anos 80, época da festa, para a época de sua juventude, anos 60 . Neste salto temporal de décadas, só permanecem os personagens remoçados, e um "insolúvel" balão metalizado que veio parar da festa dos anos 80 nos corredores da Escola dos anos 60. Em princípio a volta de Sue ao passado lhe permitiria rever seu precipitado casamento com Charlie, que na época sonhava ser cantor, e do qual está divorciada na época da festa, ambos carregando várias frustrações por causa das decisões afoitas do passado.

Em outros filmes da atualidade, há uma clara tendência em unir no curto tempo de um filme temporalidades cada vez mais distantes e que parecem irreconciliáveis fora do âmbito da narrativa em que se encontram. E' o que ocorre, por exemplo, em Highlcmder, o Guerreiro Imortal, de Russel Mulcahy (EUA, 1986). Trata-se da história de Connor MacLeod, guerreiro imortal, nascido na Escócia do século XVI, onde trava seu primeiro combate com Kurgan, outro guerreiro imortal, seu inimigo. A única forma de morte para os "imortais" é ser decapitado por um de seus pares. As lutas se sucedem até que reste apenas um deles. Da Escócia do século XVI, a história dá um salto de quatro séculos para a Nova Iorque de 1985.

Connor MacLeod é o vencedor. As mortes dos guerreiros, como a de Ramírez pela espada de Kurgan e a do próprio Kurgan, são enfatizadas por efeitos especiais - raios, explosões, fogo - que serão levados ao paroxismo na seqüência II do filme, provável herança da atividade de Mulcahy na produção de videoclipes.

Highlander traz o tema da imortalidade do ser humano, assim como os inúmeros vampiros, recentemente revistos em $O$ Vampiro de Briart Stocker de Francis Ford Coppola, também revisitados na novela Vamp, da Rede Globo, e na série televisual, Maldição Eterna, da Rede Record.

No âmbito dos filmes, talvez um dos exemplos mais belos e origi- 
nais seja The Navigator - mima Odisséia no Tempo, de Vicent Ward (Nova Zelândia, 1988).

0 filme traz a história de um vilarejo da Cúmbria, em 1348, onde os mineradores trabalham sob ameaça da peste negra que assola a Europa. O menino Griffin recebe em sonhos a mensagem de que uma expedição subterrânea, numa caverna enorme, poderá conduzi-los a uma "cidade celestial" Lá, se conseguirem forjar uma cruz e colocá-la no topo da catedral, poderão ser salvos da peste. Griffin e um pequeno grupo de mineradores partem para a viagem subterrânea e chegam a uma metrópole do século XX literalmente rompendo o asfalto da rodovia que conduz à cidade. Aparvalhados, em meio ao tráfego dos carros em alta velocidade, os mineradores, depois de várias peripécias, chegam à metrópole. Se a intenção do realizador era, de fato, mostrar a metrópole do século XX filtrada pelos olhos do homem medieval, ela tem um nítido caráter infernal. Os homens medievais buscam a Igreja como ponto central da urbe, símbolo materializado do poder espiritual unido ao terreno. Mas a metrópole capitalista do século XX traz numerosos edifícios que são símbolo de outro poder: o econômico. Mineradores de outra era se perdem num espaço simbólico de um tempo que lhes é estranho. Olham aterrorizados a coleção de imagens dos múltiplos televisores, aparentemente concretas, mas não "palpáveis" Uma realidade aterrorizante e desconhecida. A metrópole do século XX é uma espécie de "inferno" para o homem medieval.

\section{Tempos, Nuanças Temporais e Audiovisuais}

O cinema e os audiovisuais cinéticos em geral oferecem uma sugestão poderosa do fluir temporal através da ilusão da imagem em movimento. Paradoxalmente, os discursos que estes meios de comunicação veiculam manifestam uma surpreendente pobreza no tocante às possibilidades de expressão das diferentes nuanças temporais possíveis. Nos longos anos dedicados ao estudo das adaptações fílmicas e televisuais da literatura comprovamos isso.

A língua, instrumento da literatura, traz um número ponderável de 
variáveis para expressar as três temporalidades básicas: passado/presente/futuro. Se considerarmos tão-somente o passado, temos os pretéritos perfeito, imperfeito, mais-que-perfeito, por exemplo. Nos discursos audiovisuais, a maioria das nuanças temporais nos é dada pela organização seqüencial dos planos. Para diferenciar as ações da narrativa unías das outras, tais discursos só dispõem das seguintes temporalidades básicas: a /anterioridade/ temporal de uma ação em relação ao presente ó dada pelos flash-backs, enquanto a /posterioridade/ nos é dada pelos flash-forwards, e... c'est fini.

$\mathrm{Na}$ organização sintática do discurso filmico e sobretudo na organização do discurso televisual, já de per si descontínuo, as possibilidades de alternância entre essas temporalidades básicas é limitada, posto que o excesso nessa estratégia prejudicaria a inteligibilidade do discurso. As linguagens filmica e televisual já têm algumas codificações que facilitam a apreensão dos diferentes tempos dos quais o discurso trata. Convencionou-se que, em filmes coloridos, o passado é geralmente veiculado em preto e branco (como no cinema e na TV antigos). Muitos filmes, como Buich Cassidy, trazem o passado na cor sépia, herdada das fotografias antigas. No entanto, não se trata de uma codificação tão forte e formalizada como ocorre no caso dos tempos verbais da língua.

A TV brasileira é pródiga em exemplos ilustrativos das diferentes temporalizações dos discursos audiovisuais. Chapadão de Bugre, minissérie da Rede Bandeirantes, fez ampla utilização de. flash-backs em preto e branco, imagens espelhadas, câmera lenta para expressar um dos momentos cruciais da narrativa: a traição de Maria do Carmo com o filho do patrão, enquanto seu noivo, José de Arimatéia estaria viajando. Essa ação determina todo o programa narrativo de "vingança" de José de Arimatéia. Muitas vezes, no entanto, acontecimentos futuros apareceram expressos através de técnicas similares. Tal procedimento resultou em algumas dificuldades para a decodificação dos espectadores, sobretudo daqueles que não tivessem lido o romance original homônimo de Mário Palmério, aliás bem mais parcimonioso do que a minissérie no uso de alternâncias entre as diferentes temporalidades. 
Já a novela, formato muito mais extenso que o mencionado, a qual o espectador pode começar a seguir a qualquer altura da trama, parece ser bem menos propicia a grandes experimentações na temporalização. Ao que parece, urna das dificuldades maiores da novela Amazônia, da Rede Manchete, em termos de recepção, foi precisamente o intricado jogo temporal. Jorge Durán, experimentado roteirista de cinema, concebeu uma história em que os mesmos atores participavam de duas tramas distantes no tempo: a Amazonia do ciclo da borracha e a Amazônia do futuro. Um dos personagens, Caio Mangabeira (Marcos Palmeira), tinha uma capacidade paranormal para ver acontecimentos situados em tempos passados. Este estratagema, no entanto, não parece ter constituído um elo suficientemente claro e forte para a união de duas temporalidades tão distintas, embora ocorridas num mesmo espaço. A $\mathrm{I}^{\mathrm{a}}$ fase da novela foi encerrada de uma forma um tanto abrupta e a $2^{\text {a }}$ fase da trama limitou-se à abordagem da Amazônia do ciclo da borracha.

Walter George DURST (1990), consagrado roteirista de TV, em entrevista pessoal que nos foi concedida, revelou considerar limitadas as possibilidades de jogo com as diferentes temporalidades na TV, não só porque o espectador pode começar a seguir uma série em qualquer momento pontual da trama, como também pelo fato de que o próprio discurso televisual já é necessariamente descontínuo e fragmentado, devido aos intervalos para os comerciais. Dentro dessa concepção, o roteirista optou por colocar todos os episódios de Grande Sertão: Veredas em ordem cronológica, quando o romance original prima por constantes idas e vindas, no discurso de Riobaldo, entre temporalidades diversas, estratégia bem mais pertinente ou viável no literário do que nos audiovisuais cinéticos, como vinhamos detalhando.

\section{Depois dos "Beats" e dos "Beatles", vem os "Bits"}

No caminho da tecnologia em direção ao século XXI, as formas de representação analógica - cinema, TV, vídeo - vão gradativamente cedendo lugar à representação digital, de dois dígitos - zero e um - o bit.

significação 11/12 
Surge sua majestade o computador - orquestrando uma série de novos casamentos possíveis. Do universo fragmentado da mídia atual passamos ao da multimídia e hipermídia. A TV "conversa" com o telefone, o $\mathrm{CD}$ é tocado no computador, o computador "conversa" com o vídeo etc... propiciando uma espécie de interatividade delirante que Marcelo Tass chamou, com muito humor, de "promiscuidade cibernética"

No passado, o cinema, a TV e o vídeo alteraram substancialmente as formas de representação das imagens prévias, eminentemente estáticas, captando analógicamente o movimento, inserindo de forma incisiva a idéia do fluir temporal na imagem.

Hoje, a revolução da imagem digital nos obriga, de novo, a repensar o fazer artístico à luz do avanço tecnológico, derrubando fronteiras consagradas entre o concreto c o abstrato, o figurativo e o não-figurativo, entre outras.

Aparentemente, o acesso a essa divertida e instigante "promiscuidade cibernética" está aberto a todos, basta pôr os dedos no teclado do computador. A simplicidade é enganosa, no entanto, posto que as imagens digitais nos transportam para o sofisticado e complexo âmbito dos modelos, dos simulacros, das operações matemáticas, dos programas, enfim, que regem a elaboração dessas imagens emblemáticas de um "admirável mundo novo" em gestação. Apenas alguns happy few já lidam com essas maravilhosas imagens que podem ser escaneadas, reduzidas, expandidas, texturizadas, iluminadas, tridimensionalizadas... entre outros! Mas até chegar a essas imagens digitais, muitos programadores queimaram seu fosfato, muitos profissionais de computação gráfica gastaram rios de memória do computador para chegar ao resultado final. $\mathrm{O}$ Pantagruel do século XXI devora bits. O sentido do tempo que já mudou substancialmente com a imagem eletrônica é subvertido, de novo, com a imagem digital. Para que nós, usuários do terceiro mundo, possamos chegar até lá, ao século XXI, fica claro que: "No meio do caminho tinha um computador"... com o perdão de Drummond, é fclaro! 
Bibliografia

CALABRESE, Ornar. (1984). Analisi, Barcelona, n. 9.

DELEUZE, Giles. (1985). Cinema - a imagem-movimento. São Paulo, Brasiliense.

(1986). La imagem - tiempo. Estúdios sobre cine z. México, Paidós.

DURST, Walter George. (1990). Walter George Durst: depoimento (11/90). São Paulo. Entrevista concedida a Anna Maria Balogh. Acervo sonoro.

ECO, Umberto. Rápida utopia. Veja, São Paulo, abril. 25 anos. Reflexões para o futuro.

ECO, Umberto e CALABRESE, Omar. (1990). El tiempo en lapintura. Mi lano, Mondadon.

KINDER, Marsha. (1987). Music, video and the spectador: television, ideology and dream. In: NEWCOMB, H. Television - the criticai view Oxford, Oxford University Press.

MACHADO, Arlindo. (1988). A imagem digital. Notas para uma abordagem Semiótica. Face. Revista de Semiótica e Comunicação. São Paulo, 1 (1): 53-69, jan./jun.

(1989). A imagem eletrônica: problemas de representação. Face.

Revista de Semiótica e Comunicação. São Paulo, 2(1): 69-81, jan./ jun.

PAZ, Octavio. (1969). Corriente alterna. México, Siglo XXI.

. (1974). Los hijos dei Limo. Barcelona, Seix Barrai.

SEGRE, Cesare. (1986). As estruturas e o tempo. São Paulo, Perspectiva.

SZÁMOSI, Géza. (1988). Tempo e Espaço: as dimensões gêmeas. Rio de Janeiro, Zahar.

TARKOVSKY, Andrei. (1987). Sculpting in time - reflections on the cinema. London, Bodley Head.

URRUTIA, Jorge. (1984). Imago litterae. Cine. Literatura. Sevilla, Alfar.

VIRILIO, Paul e LOTRINGER, Silvere. (1984). Guerra Pura. A militarização do cotidiano. São Paulo, Brasiliense. 